\title{
EFFECTS OF A STEPS/DAY PROGRAMME WITH EVALUATION IN PHYSICAL EDUCATION ON BODY MASS INDEX IN SCHOOLCHILDREN 11-12 YEARS OF AGE
}

\author{
Alberto Grao-Cruces ${ }^{1}$, Rafael Ruiz-López ${ }^{2}$, José-Enrique Moral-García ${ }^{3}$, \\ Alberto Ruiz-Ariza ${ }^{2}$, and Emilio J. Martínez-López ${ }^{2}$ \\ ${ }^{1}$ Department of Physical Education, School of Education Science, University of Cádiz, Spain \\ ${ }^{2}$ Research group HUM 943 Laboratory, Department of Didactic of Musical, \\ Plastic and Body Expression, School of Educational Sciences, University of Jaén, Spain \\ ${ }^{3}$ School of Education, Pontifical University of Salamanca, Spain
}

Original scientific paper

UDC: $796.015 .5-053.5: 371.3$

\begin{abstract}
:
The aim of the study was to assess the effects that a steps/day programme may have on body mass index (BMI) among primary education students ( $11.37 \pm 0.48$ years). A six-week controlled trial with a follow-up was completed with an experimental group $(\mathrm{N}=66$, pedometer + steps/day programme + reinforcement programme in their physical education (PE) marks + weekly follow-up in PE), and a control group ( $\mathrm{N}=76)$. Omron HJ-152-E2 pedometers were used. Normoweight students complied with programme requirements to a greater extent than their overweight counterparts ( $72.7 \mathrm{vs} 59.1 \%$ ). The programmed minimum number of $12,000 \mathrm{steps} /$ day for boys and 10,000 for girls was exceeded by $83 \%$ of boys and $60 \%$ of girls. The differences in the number of steps/day between boys $(14,274)$ and girls $(10,626)$ were significant across all the measured periods $(\mathrm{p}<.05)$. The results show that the teenagers who complied with the programme requirements reduced their BMI significantly after the intervention $(p<.001)$ and this reduction persisted for six weeks after the programme $(\mathrm{p}<.001)$. In conclusion, the six-week programme of 12,000 steps/day for boys and 10,000 for girls, jointly with a reinforcement programme in their PE marks and weekly follow-up by their PE teacher, reduces BMI significantly in 11-12-year-old schoolchildren. Monitored steps/day programmes in the PE curriculum increase out-of-school physical activity and reduce BMI in 11-12-year-old schoolchildren.
\end{abstract}

Key words: overweight, pedometer, physical activity, sedentary lifestyle

\section{Introduction}

One of the main concerns of world health administration is the growing increase in body fat observed in the population of developed and developing countries (World Health Organization, 2010). It has been proved that schools can play a relevant role in the prevention and control of childhood and youth overweight (Hardman, 2008; MartínezLópez, Grao-Cruces, Moral-García, \& PantojaVallejo, 2012; Martínez-López, Zagalaz, Ramos, $\&$ de la Torre, 2010). In this context, physical education $(\mathrm{PE})$ has become a most suitable framework for the development of programmes aimed at increasing children's physical activity (PA) levels, specifically through the application of methods that positively influence their out-of-school behaviour (Elder, et al., 2010; Viira \& Koka, 2012). An example of this is the use of pedometers as an instrument to quantify the number of steps a day that students take. Pedometer use allows PE teachers to assess students' out-ofschool PA partially and, therefore, to intervene in a more accurate and personalized way (MartínezLópez, et al., 2012).

The use of pedometers has been considered very promising because it leads to increased PA in students (Kang \& Brinthaupt, 2009), and allows PA monitoring during out-of-school time (Belton, Brady, Meegan, \& Woods, 2010; Flohr, Todd, \& Tudor-Locke, 2009; Lubans \& Morgan, 2009). The basic premise through which the use of pedometers can be a motivational element to increase schoolchildren's PA is that it provides immediate feedback of how the choice of their behaviour affects their PA. However, pedometer feedback alone did not appear to be sufficient to increase PA. Setting realistic goals of steps is a key factor in pedometer interventions (Lubans, Morgan, \& Tudor-Locke, 2009). Extra motivation such as extra marks in PE, 
that is, not just the use of the pedometer and the achievement of certain goals, may play a crucial role in increasing PA (Martínez-López, et al., 2012).

Previous research such as Finnerty, Reeves, Dabinett, Jeanes, and Vögele (2010), Le Masurier and Corbin (2006), and Tudor-Locke, Lee, Morgan, Beighle, and Pangrazi (2006) reveal that: 1) boys take more steps than girls; 2) most steps are taken during free time; 3 ) primary education students walk more than their secondary education counterparts; and 4) students with higher PA levels accomplish more steps/day. Lubans et al. (2009) observed that a 4-week pedometer intervention with schoolchildren successfully increased PA levels in the least active students.

Despite this evidence, some aspects of the use of pedometers in PE remain a source of debate, such as the number of steps to be taken, pedometer didactic management in PE, and the effects of prolonged pedometer use on BMI according to age and gender. Although 10,000 steps/day can be taken as a valid objective to classify adults as active (Tudor-Locke \& Bassett, 2004), the main recommendations for teenagers range between 11,000 and 16,500 steps/day (Beets, Bornstein, Beighle, Cardinal, \& Morgan, 2009). McCormack, Rutherford, Giles-Corti, Tudor-Locke, and Bull (2011) remark that at least 16,000 steps/day are necessary to improve body composition, and Tudor-Locke et al. (2004) set the minimum for this objective to be achieved at 15,000 in boys and 12,000 in girls. Dollman, Olds, Esterman, and Kupke (2010) reduce the amount of steps recommended to improve body weight to $12,000,11,000$ and 10,000 steps/day for 5-12-year-old boys, 13-16-year-old boys, and 5-16-year-old girls, respectively. Martínez-López et al. (2012) observed a reduction in BMI and body fat (measured by electrical bioimpedance) after a six-week programme of 12,000 steps/day in overweight teenage boys and 10,000 steps/day in girls.

Although pedometers provide no information on PA intensity, they have been reported to provide highly objective data (Senne, Rowe, Boswell, Decker, \& Douglas, 2012). Indeed, pedometers have been used in American schools as a means to increase PA levels among the youth, as well as to control overweight in schoolchildren, and for the national PA-level follow-up among the Canadian youth (Craig, Tudor-Locke, Cragg, \& Cameron, 2010). This practice is not widespread in European countries, and little is known about its application effects on BMI in schoolchildren. It has been claimed that issues originating from pedometer use with schoolchildren do not lie so much in the degree of responsibility shown by children or its difficult usage, as in the efficiency of the educational programme within which the experience is developed (Martínez-López, et al., 2012). Few studies have implemented pedometer use in pre-adoles- cents (11-12-year olds), therefore children's degree of fulfilment with the goal of steps/day and effects of an intervention programme launched within PE remain unknown.

Partly for these reasons, the main objective of the present study was to assess the effects of a sixweek pedometer intervention programme aimed at promoting PA among primary education students, as well as the BMI variations within six weeks after the intervention (detraining period). Specifically, the aims were: 1) to quantify the number of steps taken by the participants during the programme, separating out-of-school from at-school time, and weekdays from weekends; and 2) to assess the effects of the programme on BMI according to the students' degree of fulfilment.

\section{Methods}

\section{Research design}

The experiment was a control trial with a follow-up. The experimental group completed a programme based on the set minimum of steps/ day, and a pedometer was used for evaluation and follow-up purposes. The control group was not involved in a step/day programme and did not use pedometers. The participants' BMI was measured at three time points: pre-intervention, immediately post-intervention and after the six-week retention period in both groups. The research was carried out between January and June 2012.

\section{Participants}

One hundred and fifty-one students from four primary schools of southern Spain took part in this study. One hundred and fifty-six students volunteered out of the potential sample of $175 \mathrm{six}$ graders. The structure used for group formation and the anthropometric features of the schoolchildren in each group are shown in Figure 1 and Table 1 respectively.

\section{Measures and procedures}

The number of steps/day was measured by means of Omron HJ-152-E2 pedometers (Omron, Hoofddorp, Netherlands). High reliability in steps/ day measurement had already been proved for similar pedometers, compared with more complex and expensive technologies (Jago, et al., 2006). The participants' BMI was calculated from their weight and height measures $\left(\mathrm{kg} / \mathrm{m}^{2}\right)$. A type-B class-III ASIMED weighing scale (Spain) and a portable SECA 214 (SECA Ltd., Germany) height rod were used for these purposes. The research was performed with an experimental group $(\mathrm{N}=66$, after nine participants dropped out from the initial 75 -participant group) and a control group ( $\mathrm{N}=76)$. The design of the study stages followed the Spanish 


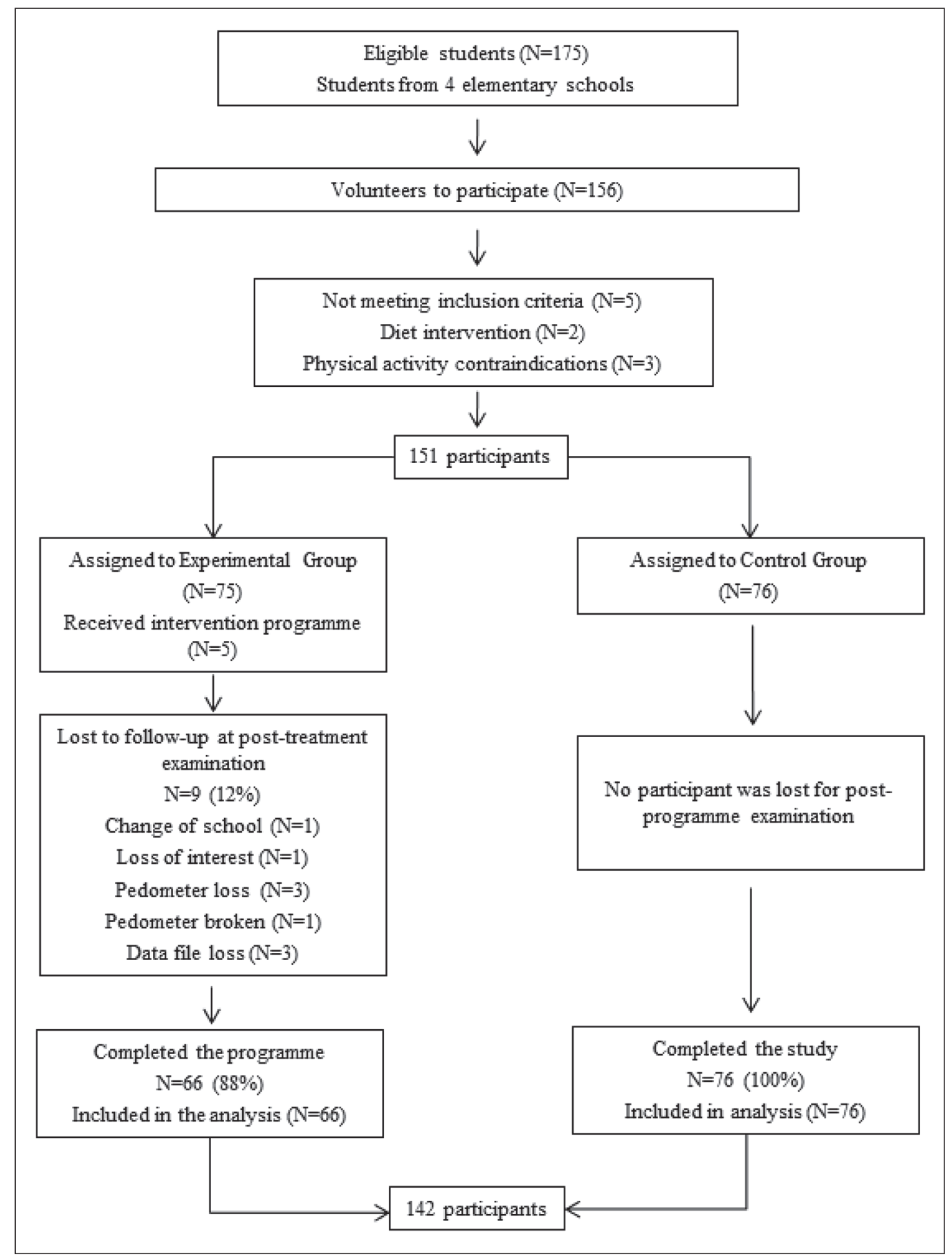

Figure 1. Flow of participants throughout programme implementation.

Table 1. Anthropometric features of participants at baseline

\begin{tabular}{llccc}
\hline Variable & & $\begin{array}{c}\text { Control } \\
\text { group }(\mathbf{N}=\mathbf{7 6})\end{array}$ & $\begin{array}{c}\text { Experimental } \\
\text { group }(\mathbf{N}=66)\end{array}$ & p value $^{\mathrm{a}}$ \\
\hline Age $($ years) & & $11.45 \pm 0.50$ & $11.29 \pm 0.45$ & .050 \\
Weight $(\mathrm{kg})$ & $48.99 \pm 13.52$ & $49.99 \pm 12.88$ & .656 \\
Height $(\mathrm{m})$ & $1.53 \pm 0.07$ & $1.52 \pm 0.06$ & .789 \\
Body Mass Index $\left(\mathrm{kg} / \mathrm{m}^{2}\right)$ & & $20.69 \pm 4.65$ & $21.23 \pm 4.59$ & .479 \\
Gender [N(\%)] & Female & $39(48.7)$ & $42(63.6)$ & .052 \\
& Male & $37(51.3)$ & $24(36.4)$ & .228 \\
\hline
\end{tabular}

Note. Values are represented as means $\pm \mathrm{SD}$. ap-values represent inter-group comparison. 
laws that regulate clinical research in humans (Royal Decree 561/1993), the Organic Law on Personal Data Protection 15/1999, and the necessary ethics principles in the 2013 review of the Declaration of Helsinki. An induction meeting was held to inform the participants, their parents and PE teachers of the nature and objectives of the research. Informed written consents were signed by the parents and authorities of the schools involved, upon approval given by the School Council. For ethical reasons, the members of the control group were given an opportunity to take part in a PA encouragement programme with pedometers.

Programme implementation. Each student had to comply with the plan consisting of the minimum of 12,000 steps/day for boys and 10,000 for girls (Martínez-López, et al., 2012). The students were asked to wear their pedometers for the whole day, except when in bed and in the shower. The control group did not use pedometers, but their anthropometric data were recorded periodically, at the same time points as for the experimental group. The participants in the experimental group were urged to consult their number of steps at any time, as a means to check their degree of daily compliance with the programme. To increase their motivation for $\mathrm{PA}$, the programme granted up to two extra marks in the PE subject according to achieved number of daily steps (Table 2), which was controlled weekly by the PE teacher.

Table 2. Additional marks in Physical Education (PE) according to programme fulfilment

\begin{tabular}{ccc}
\hline $\begin{array}{c}\text { Steps a day } \\
\text { (boys) }\end{array}$ & $\begin{array}{c}\text { Steps a day } \\
\text { (girls) }\end{array}$ & $\begin{array}{c}\text { Additional } \\
\text { marks in PE }\end{array}$ \\
\hline$<12,000$ & $<10,000$ & 0 \\
$12,000-12,999$ & $10,000-10,999$ & 1 \\
$13,000-13,999$ & $11,000-11,999$ & 1.3 \\
$14,000-14,999$ & $12,000-12,999$ & 1.6 \\
$15,000-15,999$ & $13,000-13,999$ & 1.8 \\
$\geq 16,000$ & $\geq 14,000$ & 2 \\
\hline
\end{tabular}

Measurement of results. The participants recorded their daily steps for six weeks. The number of steps taken during school time (including a commute to and from school) and during the whole day were recorded every day by the children (previously trained) in the presence of their parents. Every week the research staff checked with the internal memory of each pedometer that the registered steps were correct. The steps on weekdays and during weekends were also quantified. Anthropometric measurements of each participant were taken three times (pre- and post-intervention and postdetraining period), separated by six-week periods between the measurements (total time $=12$ weeks).

\section{Statistical analysis}

The initial comparison between groups of continuous variables was carried out by means of Student's $t$-test for independent samples and chisquare test for categorical variables. The repeated measures method of the general linear model was used for differences in dependent variables (steps and BMI). Four analyses of variance were completed: 1) ANOVA two(gender) $\times$ two(time), to analyse steps/day differences by gender (boys vs girls) after six weeks of experiment; 2) ANOVA two(type) $\times$ two(time), to study steps/day differences by body type (normoweight vs. overweight); 3) ANOVA two(group) $\times$ three(time), to analyse BMI results in each group (control vs. experimental) at pre-intervention, post-intervention, and postdetraining measurement points (this analysis was completed separately for boys and girls due to the programme's different steps/day requirements); and 4) ANOVA two(programme) $\times$ three(time), to analyse BMI scores according to programme compliance criterion (compliance vs. failure to comply with the prescription) in pre-, post-intervention and post-detraining measurements. The main interest was the interaction effect. Post-hoc analysis was adjusted by means of Bonferroni. For all the analyses, a 95\% confidence level was used $(\mathrm{p}<.05)$. The analyses were completed using the statistical software package for social sciences SPSS (v.19 for MS Windows). The relative percentage change between the pre- and post-measures was calculated as follows: ((post measure-pre measure)/pre measure) 100 .

\section{Results}

After six weeks of intervention, normoweight students complied with the stipulated minimum of steps to a greater extent than their overweight counterparts ( 72.7 vs. $59.1 \%)$. Students between 11 and 12 years of age took an average number of 11,952 steps/day (boys=14,274; girls=10,626). The average number of steps/day was 12,345 on weekdays and 10,969 at the weekends.

\section{Steps/day analysis of variance}

The results of the two(gender) $\times$ two(time) ANOVA on the average number of steps/day is shown in Table 3. Boys took 22\% more steps/day than girls and scored higher on steps/day at all the periods measured: in-school $\left(\mathrm{p}=.004, \mathrm{Eta}^{2}=.150\right.$, $1-\beta=.837)$, out-of-school $\left(\mathrm{p}<.001, \quad \mathrm{Eta}^{2}=.237\right.$, $1-\beta=.974)$, weekdays $\left(\mathrm{p}<.001, \mathrm{Eta}^{2}=.313,1-\beta=.999\right)$, weekends $\left(\mathrm{p}=.004, \mathrm{Eta}^{2}=.135,1-\beta=.842\right)$, and whole week $\left(p<.001, \mathrm{Eta}^{2}=.297,1-\beta=.998\right)$. After six weeks of intervention the average number of steps/day decreased by $18.1 \%$. The interaction effect (gender $\times$ time) turned out to be significant 
Table 3. Results of ANOVA two(gender) $\times$ two(time) showing the effect of the six-week intervention on the number of steps a day in 11-12-year-old boys $(N=24)$ and girls $(N=42)$. Steps are shown as: on weekdays in school time (including to and from school commute), on weekdays in out-of-school time, on working days (steps a day from Monday to Friday), during weekends (steps a day on Saturday and Sunday), and throughout the whole week (average number of steps a day for the whole week)

\begin{tabular}{|c|c|c|c|c|c|c|}
\hline \multirow[b]{2}{*}{ Steps a day } & \multirow[b]{2}{*}{ Gender } & \multirow[b]{2}{*}{$\begin{array}{c}\text { Pre } \\
\text { M(SD) }\end{array}$} & \multirow[b]{2}{*}{$\begin{array}{l}\text { Post } \\
\text { M(SD) }\end{array}$} & \multicolumn{3}{|c|}{ Effect } \\
\hline & & & & $\begin{array}{c}\text { Gender } \\
p \\
E_{t a}^{2} \\
1-\beta\end{array}$ & $\begin{array}{c}\text { Time } \\
p \\
\text { Eta } \\
1-\beta\end{array}$ & $\begin{array}{c}\text { Gender } \times \text { Time } \\
\text { p } \\
E t a^{2} \\
1-\beta\end{array}$ \\
\hline \multirow[b]{2}{*}{ School hours } & Boys & $6,637(2,286)$ & $6,441(1,769)$ & .004 & .273 & .654 \\
\hline & Girls & $5,450(2,221)$ & $4,984(997)$ & $\begin{array}{l}.150 \\
.837\end{array}$ & $\begin{array}{l}.024 \\
.193\end{array}$ & $\begin{array}{l}.004 \\
.073\end{array}$ \\
\hline \multirow[b]{2}{*}{ Out-of-school hours } & Boys & $10,942(2,503)$ & $6,761(3,097)$ & $<.001$ & $<.001$ & .015 \\
\hline & Girls & $7,816(2,175)$ & $5,463(2,448)$ & $\begin{array}{l}.237 \\
.974\end{array}$ & $\begin{array}{c}.554 \\
>.999\end{array}$ & $\begin{array}{l}.111 \\
.698\end{array}$ \\
\hline \multirow{2}{*}{ Weekdays } & Boys & $17,579(3,532)$ & $13,202(3,125)$ & $<.001$ & $<.001$ & .070 \\
\hline & Girls & $13,266(3,054)$ & $10,447(2,543)$ & $\begin{array}{l}.313 \\
.999\end{array}$ & $\begin{array}{c}.553 \\
>.999\end{array}$ & $\begin{array}{l}.055 \\
.443\end{array}$ \\
\hline \multirow[b]{2}{*}{ Weekends } & Boys & $11,756(3,228)$ & $12,409(4,948)$ & .004 & .348 & .048 \\
\hline & Girls & $10,715(3,504)$ & $8,837(2,958)$ & $\begin{array}{l}.135 \\
.842\end{array}$ & $\begin{array}{l}.015 \\
.154\end{array}$ & $\begin{array}{l}.066 \\
.512\end{array}$ \\
\hline \multirow{2}{*}{ Whole week } & Boys & $15,638(2,918)$ & $12,976(3,134)$ & $<.001$ & $<.001$ & .643 \\
\hline & Girls & $12,324(2,839)$ & $9,984(2,356)$ & $\begin{array}{l}.297 \\
.998\end{array}$ & $\begin{array}{c}.413 \\
>.999\end{array}$ & $\begin{array}{l}.004 \\
.074\end{array}$ \\
\hline
\end{tabular}

Table 4. Results of ANOVA two(type) $\times$ two(time) showing the average number of steps taken by normoweight vs overweight students after six weeks of intervention. Analysis was completed separately for boys ( $N=18$ normoweight and six overweight) and girls $(N=26$ normoweight and 16 overweight). Steps are shown as: on weekdays in school time (including to and from school commute), on weekdays in out-of-school time, on working days (steps a day from Monday to Friday), during weekends (steps a day on Saturday and Sunday), and throughout the whole week (average number of steps a day for the whole week)

\begin{tabular}{|c|c|c|c|c|c|c|c|}
\hline \multirow[b]{2}{*}{ Steps a day } & \multirow[b]{2}{*}{ Gender } & \multirow[b]{2}{*}{ Type } & \multirow[b]{2}{*}{$\begin{array}{l}\text { Pre (week one) } \\
\text { M(SD) }\end{array}$} & \multirow[b]{2}{*}{$\begin{array}{l}\text { Post (week six) } \\
\text { M(SD) }\end{array}$} & \multicolumn{3}{|c|}{ Effect } \\
\hline & & & & & $\begin{array}{c}\text { Type } \\
\text { p } \\
\text { Eta }^{2} \\
1-\beta\end{array}$ & $\begin{array}{c}\text { Time } \\
\mathbf{p} \\
\mathrm{Eta}^{2} \\
1-\beta\end{array}$ & $\begin{array}{c}\text { Typex } \\
\text { Time } \\
p \\
\text { Eta }^{2} \\
1-\beta\end{array}$ \\
\hline \multirow{5}{*}{ School hours } & \multirow[b]{2}{*}{ Boys } & Normoweight & $6,775(2,386)$ & $6,673(1,764)$ & .491 & .633 & .765 \\
\hline & & Overweight & $6,280(2,220)$ & $5,839(1,826)$ & $\begin{array}{l}.030 \\
.102\end{array}$ & $\begin{array}{l}.015 \\
.074\end{array}$ & $\begin{array}{l}.006 \\
.059\end{array}$ \\
\hline & \multirow{3}{*}{ Girls } & Normoweight & $5,288(2,253)$ & $4,994(993)$ & .678 & .157 & .527 \\
\hline & & & & & .005 & .060 & .012 \\
\hline & & Overweight & $5,725(2,230)$ & $4,968(1,044)$ & .069 & .290 & .095 \\
\hline \multirow{4}{*}{$\begin{array}{l}\text { Out-of-school } \\
\text { hours }\end{array}$} & \multirow{2}{*}{ Boys } & Normoweight & $10,791(2,733)$ & $6,685(3,360)$ & .930 & .001 & .628 \\
\hline & & Overweight & $11,335(1,970)$ & $6,949(2,597)$ & $\begin{array}{l}<.001 \\
.051\end{array}$ & $\begin{array}{l}.482 \\
.951\end{array}$ & $\begin{array}{l}.015 \\
.075\end{array}$ \\
\hline & \multirow{2}{*}{ Girls } & Normoweight & $7,560(2,458)$ & $5,577(2,633)$ & .800 & $<.001$ & .340 \\
\hline & & Overweight & $8,288(1,680)$ & $5,356(2,156)$ & $\begin{array}{l}.002 \\
.057\end{array}$ & $\begin{array}{l}.553 \\
>.999\end{array}$ & $\begin{array}{l}.028 \\
.156\end{array}$ \\
\hline \multirow{4}{*}{ Weekdays } & \multirow{2}{*}{ Boys } & Normoweight & $17,566(3,529)$ & $13,358(3,206)$ & .850 & $<.001$ & .738 \\
\hline & & Overweight & $17,615(3,877)$ & $12,788(3,145)$ & $\begin{array}{l}.002 \\
.054\end{array}$ & $\begin{array}{l}.550 \\
.997\end{array}$ & $\begin{array}{l}.006 \\
.062\end{array}$ \\
\hline & \multirow[b]{2}{*}{ Girls } & Normoweight & $12,848(3,006)$ & $10,571(2,773)$ & .622 & $<.001$ & .106 \\
\hline & & Overweight & $14,013(3,106)$ & $10,224(2,150)$ & $\begin{array}{l}.007 \\
077\end{array}$ & $\begin{array}{r}.545 \\
>999\end{array}$ & $\begin{array}{l}.069 \\
366\end{array}$ \\
\hline \multirow{5}{*}{ Weekends } & \multirow{3}{*}{ Boys } & Normoweight & $11,551(3,319)$ & $11,824(5,206)$ & .334 & .493 & .621 \\
\hline & & & & & .047 & .024 & .012 \\
\hline & & Uverweight & T2,30T(3,198) & $13,971(4,182)$ & .157 & .102 & .077 \\
\hline & \multirow{2}{*}{ Girls } & Normoweight & $11,015(3,662)$ & $8,748(3,207)$ & .831 & .017 & .291 \\
\hline & & Overweight & $10,138(3,240)$ & $9,227(2,507)$ & $\begin{array}{l}.001 \\
.055\end{array}$ & $\begin{array}{l}.149 \\
.685\end{array}$ & $\begin{array}{l}.031 \\
.181\end{array}$ \\
\hline \multirow{5}{*}{ Whole week } & \multirow{2}{*}{ Boys } & Normoweight & $15,561(2,794)$ & $12,920(3,205)$ & .844 & .004 & .964 \\
\hline & & Overweight & $15,844(3,503)$ & $13,126(3,226)$ & $\begin{array}{l}.002 \\
.054\end{array}$ & $\begin{array}{l}.340 \\
.863\end{array}$ & $\begin{array}{c}<.001 \\
.050\end{array}$ \\
\hline & \multirow{3}{*}{ Girls } & Normoweight & $12,165(2,905)$ & $10,046(2,586)$ & .800 & $<.001$ & .554 \\
\hline & & Overweight & & & .002 & .445 & .010 \\
\hline & & Uverwergnt & $12,632(2,839)$ & $9,983(2,001)$ & .057 & .999 & .090 \\
\hline
\end{tabular}


in the number of steps/day out-of-school $(\mathrm{p}=.015$, $\left.\mathrm{Eta}^{2}=.111,1-\beta=.698\right)$ and during weekends $(\mathrm{p}=.048$, $\left.\mathrm{Eta}^{2}=.066,1-\beta=.512\right)$. A more detailed analysis of the interaction revealed that, after six weeks of experiment, the average number of steps/day in out-of-school time decreased significantly among boys ( pre $=10,942$ vs. post $=6,761, p<.001$ ), and less so among girls (pre $=7,816$ vs. post $=5,463, p<.001$ ). The number of steps/day during the weekends also decreased significantly among girls (pre $=10,715$ vs. post $=8,837, \mathrm{p}=.005$ ) after six weeks of intervention, but not among boys $(\mathrm{p}=.596)$.

The results of the two(type) $\times$ two(time) ANOVA, completed separately for boys and girls, are shown in Table 4, with the specification of the average number of steps/day taken by normoweight vs. overweight students. The data show a main time effect with a significant decrease in the number of steps/ day at the end of the intervention in out-of-school $(\mathrm{p}=.001$ for boys and $\mathrm{p}<.001$ for girls), weekday $(p<.001$ for boys and $p<.001$ for girls) and wholeweek ( $p=.004$ for boys and $p<.001$ for girls) measurements, as well as in girls also for the weekend period $(\mathrm{p}=.017)$. Neither the main type effect nor the (type $\times$ time) interaction in any of the step measurements were significant $(\mathrm{p}>.05)$.

\section{BMI analysis of variance}

Figure 2 a shows the effect of time (pre- and post-intervention and post-detraining) on participants' BMI of the experimental and control group. ANOVA two(group) $\times$ three(time) found the (group $\times$ time) interaction $\mathrm{F}(2,139)=6.385, \mathrm{p}=.002$, $\mathrm{Eta}^{2}=.044,1-\beta=.899$. A more detailed analysis revealed significantly-reduced average BMI in the experimental group after six weeks of pedometer use pre $=21.23 \pm 4.59$ vs. post $=21.00 \pm 4.36 \mathrm{~kg} / \mathrm{m}^{2}$, $\mathrm{p}<.001)$. It also revealed that the differences relative to pre-measures persisted over additional six weeks (post-detraining $=20.84 \pm 4.42 \mathrm{~kg} / \mathrm{m}^{2}, \mathrm{p}<.001$ ). No significant BMI differences were observed between any of the three measurements in the control group $(\mathrm{p}>.05)$.

Figure $2 \mathrm{~b}$ shows the effect of time (pre- and post-intervention and post-detraining) on BMI according to the steps/day programme compliance in the experimental group $(\mathrm{N}=66)$. ANOVA two(programme) $\times$ three(time) found the effect of the (programme $\times$ time) interaction $\mathrm{F}(2,63)=2.958$, $\mathrm{p}=.046, \mathrm{Eta}^{2}=.056,1-\beta=.564$. Post-hoc analysis revealed that the students who complied with the programme $(\mathrm{N}=45)$ significantly reduced their BMI ( pre $=20.62 \pm 4.58 \mathrm{~kg} / \mathrm{m}^{2}$ vs post $=20.31 \pm 4.37 \mathrm{~kg} / \mathrm{m}^{2}$; $\mathrm{p}<.001)$. Their BMI decreased further significantly throughout six weeks after the programme implementation (post-intervention vs. post-detraining $\left(20.13 \pm 4.30 \mathrm{~kg} / \mathrm{m}^{2}, \mathrm{p}=.014\right)$, and pre-intervention vs. post-detraining $(\mathrm{p}<.001)$. By contrast, the students who failed to comply with the minimum of steps/

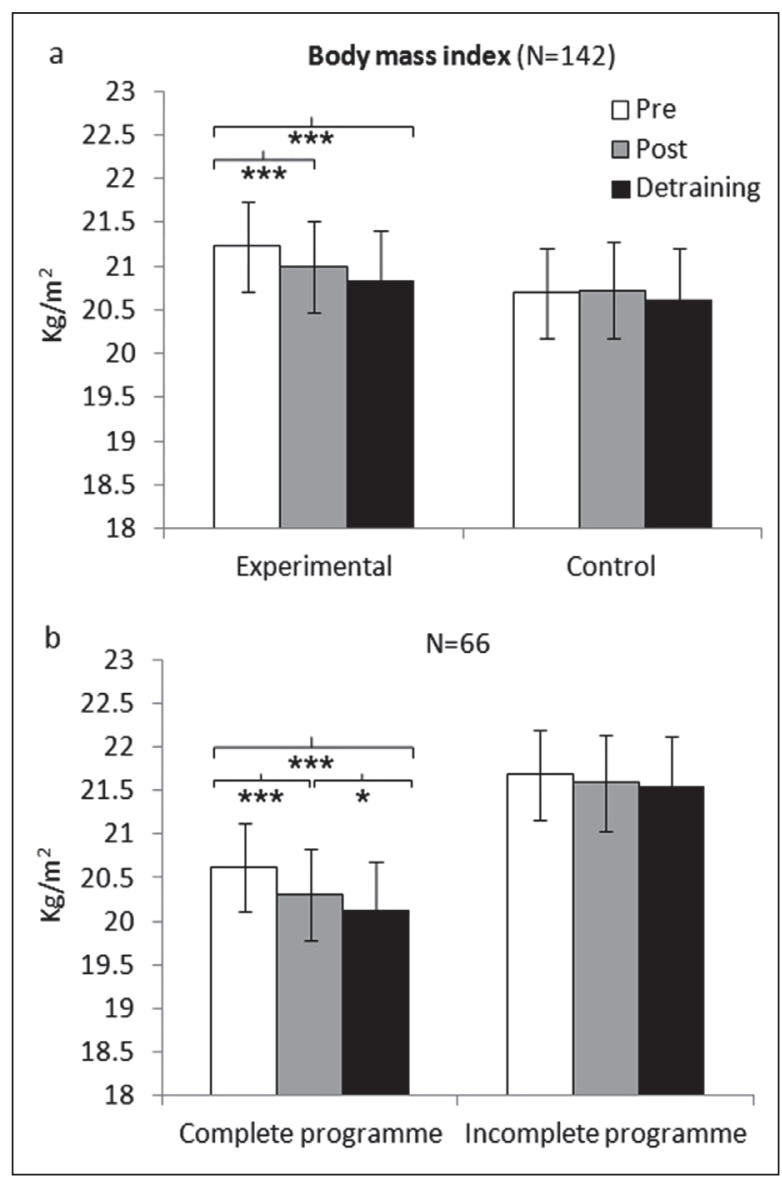

Figure 2. Effect of the six-week training on body mass index (BMI). Pre=initial measure, post=measure after six weeks, detraining=six weeks after the intervention. * and *** stand for the significant intrasubject differences: $p<.05$ and $p<.001$, respectively.

day prescribed in the programme $(\mathrm{N}=21)$ obtained similar BMI results in all the three measurements $(\mathrm{p}>.05)$.

\section{Discussion and conclusions}

This paper studies the effects of a six-week steps/day programme with pedometer in 11-12-yearold schoolchildren. The programme was welltolerated by all students, and no derived health problems were observed. The minimum of steps/ day prescribed by the programme was exceeded by $83.3 \%$ by boys and $59.5 \%$ by girls. For both genders, the average number of steps/day recorded decreased as the programme advanced. Even so, a significantly reduced BMI was observed in the students equipped with a pedometer who managed to comply with the stipulated minimum number of steps/day. This effect on BMI remains significant for six weeks more after the intervention. These results suggest that the use of monitored steps/day programmes can be included in the PE curriculum without any apparent risks for children, since they have been proven useful to improve body composition in 11-12-year-old students. 
During the six-week intervention, the average number of steps/day was higher among boys $(14,274)$ than among girls $(10,626)$. Similar gender-related differences were found by Flohr et al. (2006) (with 12,490 steps/day for boys and 10,557 for girls) in a two-week programme, and by Lubans and Morgan (2009) (with 11,865 and 9,466 steps/day) in a fourday programme. The argument that girls are physically less active than boys is unclear. Intrapersonal variables and social, cultural and perceived environments have been suggested as the main factors for gender differences in children's PA (Klinker, et al., 2014). Still, boys and girls seem to require different proposals of steps/day. The target number of steps/ day is not so clear, since the figures provided by different studies vary widely: from 10,849 and 9,652 in Hohepa, Schofield, Kolt, Scragg, and Garrett (2008) to 15,000 and 12,000 in Tudor-Locke et al. (2004) for boys and girls, respectively.

A decrease in the average number of steps/day was also observed throughout the intervention. Again, Duncan, Birch, and Woodfield (2012) and Martínez-López et al. (2012) reported a progressive decrease in the number of steps/day within four and six weeks of intervention on schoolchildren, respectively. This decrease may be explained by the fact that pedometer use involves an extra motivation of children for PA (Lubans, et al., 2009). Their quick familiarization with this device can lead to a gradual decrease in motivation and, thus, to a progressive disregard of protocol (Kahan \& Nicaise, 2011). This is, however, another controversial point, as Duncan, Birch et al. (2012) ascertained that the average number of steps/day can sometimes, after several weeks of intervention, exceed the figure obtained at the beginning of the study.

As regards the determination of the number of steps/day taken in different periods of a day and a week, a reduced (11\%) average number of steps/ day was observed during weekends compared with weekdays. These results are in line with those reported by Duncan, Schofield, and Duncan (2006) and Martínez-López et al. (2012), but they are in contrast to those reported by Belton et al. (2010), who found that six-nine-year-old children took $54.2 \%$ more steps/day during weekends than on weekdays. More than half of the steps on weekdays were taken during out-of-school time (57\%). This confirms the findings reported by Belton et al. (2010), Martínez-López et al. (2012), and TudorLocke et al. (2006), whose schoolchildren took more steps after school than during school. This result was expected, as movement possibilities at school are rather limited to break times and PE lessons. Thus, new proposals to increase quantifiable PA are necessary to increase schoolchildren's activity during school. For instance, average time devoted to active commute to and from school among teenagers is 18 minutes (Mendoza, et al., 2011), and may increase the whole-day PA by $13 \%$ (Smith, et al., 2012).

Our results show that the average number of steps/day taken by normoweight and overweight students was similar. This differs from the results obtained by Belton et al. (2010) and Olds, Ferrar, Schranz, and Maher (2011) who reported that overweight students took fewer steps/day than their normoweight counterparts. Other cross-sectional studies have also shown that the students with higher BMI are those who take fewer steps/day, for example Duncan et al. (2006) on 5-12-year-old New Zealanders, then Duncan, Birch, Al-Nakeeb, and Nevill (2012) on English primary education students, Duncan, Nevill, Woodfield, and Al-Nakeeb (2010) on 8-14-year-old British, Vicent, Pangrazi, Raustorp, Tomson, and Cuddihy (2003) on 6-12-yearold American, Australian and Swedish children, Itoi, Yamada, Watanabe, and Kimura (2012) on 11-12-year-old overweight Japanese students, and Michalopoulou et al. (2011) on 9-14-year-old Greek students. However, Martínez-López et al. (2012) observed that overweight Spanish students could follow the steps/day proposals designed for their normoweight classmates and aimed at promoting PA. The explanation that the number of steps/day was similar between the normoweight and overweight students in our study may be related to the educational programme linked to the use of pedometers. Belton et al. (2010), Duncan, Schofield, and Duncan (2007) and Olds et al. (2011) used pedometers to describe PA levels, but no improvement programme was developed. By contrast, our normoweight and overweight schoolchildren shared the same steps/day objectives, follow-up measurements, and evaluation. In the end, $83.3 \%$ of boys and $59.5 \%$ of girls complied with the programme's minimum steps/day requirements. This percentage exceeds the $32 \%$ obtained by Lubans and Morgan (2008) on teenage boys and $33 \%$ on girls, and the 58.3 and $41.2 \%$ obtained by Martínez-López et al. (2012) on overweight teenage boys and girls, respectively.

Our results demonstrated that the application of a steps/day programme with weekly followup measurements and motivation underpinned by higher PE marks lead to significantly reduced BMI in our students. These results are similar to those reported by Martínez-López et al. (2012), who reported reduced BMI in overweight teenagers after a six-week incentivized programme including the minimum of 12,000 steps/day for boys and 10,000 for girls. These results are in contrast with other studies where no minimum number of steps/day was set. For instance, Duncan et al. (2012) and Conwell, Trost, Spence, Brown, and Batch (2010) achieved no reduction after four- and 10-week interventions on 10-11-year-old and 8-18-year-old students, respectively. In our study, BMI was significantly reduced 
in the participants who complied with the minimum programme-stipulated number of steps per day. This number was respected by the normoweight students more often than by the overweight students $(72.7$ vs. 59.1\%). However, it was not necessary to reach 16,000 steps/day set by McCormack et al. (2011). In pedometer interventions, the follow-up measures to ensure compliance and evaluation process seem to be more determining to guarantee success in BMI reduction than the prescribed number of steps/day.

Few studies analysed whether the effects of pedometer interventions lasted some time after the interventions. Our results show that BMI reduction, achieved during the pedometer programme, persisted for at least six weeks after the intervention. These results contrast with those reported by Martínez-López et al. (2012) on secondary education students. This six-week-after-the-intervention BMI-reduction persistence in primary education students (11-12-year olds) may be related to a greater receptivity to reinforcement of active habits among younger students. There is evidence of other factors that may influence significant BMI reductions in this post-intervention period such as longer-lasting pedometer interventions (Richardson, et al., 2008), the inclusion of calorie restricted diet (Rodearmel, et al., 2007), higher steps/day objectives (TudorLocke, Craig, Cameron, \& Griffiths, 2011), or the use of participant-paid pedometers (MartínezLópez, et al., 2012). We believe that three other factors can have a decisive impact on pedometer use: 1) prescription of the minimum programme requirements adapted to the participants' age and gender; 2) motivation stimulation by extra PE grades awarded; and 3) weekly follow-up and control by PE teachers.

Admittedly, this study has a number of limitations. It did not measure the participants' PA before the programme initiations, so the influence of pedometer use on their PA cannot be established accurately. Pedometers do not record intensity of PA or other types of PA like cycling or swimming. The lack of motivational aspects may have been another limitation. Still, wrong data, whether intentional or not, has been miminized by a digital control of the number of steps taken by a reliable and inexpensive instrument (Craig et al., 2010). Finally, a relatively low price of pedometers, especially compared with more expensive devices like acceloremeters, $(\approx 20 €)$, allows a large-scale use among schoolchildren.

In conclusion, a six-week programme of 12,000 steps/day for boys and 10,000 for girls, supported by a PE reinforcement programme and weekly followup from PE teachers, can generate significant BMI reductions in 11-12-year-old children. This significant BMI reduction was observed to persist six weeks after the intervention in the students who had managed to comply with the steps/day programme. The use of monitored steps/day programmes in the PE curriculum successfully increases out-of-school $\mathrm{PA}$ and reduces BMI in 11-12-year-old students.

\section{References}

Beets, M.W., Bornstein. D., Beighle, A., Cardinal, B.J., \& Morgan, C.F. (2010). Pedometer-measured physical activity patterns of youth: A 13 country review. American Journal of Preventive Medicine, 38(2), 208-216.

Belton, S., Brady, P., Meegan, S., \& Woods, C. (2010). Pedometer step count and BMI of Irish primary school children aged 6-9 years. Preventive Medicine, 50(4), 189-192.

Conwell, L.S., Trost, S.G., Spence, L., Brown, W.J., \& Batch, J.A. (2010). The feasibility of a home-based moderateintensity physical activity intervention in obese children and adolescents. British Journal of Sports Medicine, 44(4), 250-255.

Craig, C.L., Tudor-Locke, C., Cragg, S., \& Cameron, C. (2010). Process and treatment of pedometer data collection for youth: The Canadian Physical Activity Levels Among Youth Study. Medicine \& Science in Sports \& Exercise, 42(3), 430-435.

Dollman, J., Olds, T.S., Esterman, A., \& Kupke, T. (2010). Pedometer step guidelines in relation to weight status among 5- to 16-year-old Australians. Pediatric Exercise Science, 22(2), 288-300.

Duncan, J.S., Birch, S., Al-Nakeeb, Y., \& Nevill, A.M. (2012). Ambulatory physical activity levels of white and South Asian children in Central England. Acta Paediatrica, 101(4), 156-162.

Duncan, J.S., Birch, S., \& Woodfield, L. (2012). Efficacy of an integrated school curriculum pedometer intervention to enhance physical activity and to reduce weight status in children. European Physical Education Review, 18(3), 396-407.

Duncan, M.J., Nevill, A., Woodfield, L., \& Al-Nakeeb, Y. (2010). The relationship between pedometer-determined physical activity, body mass index and lean body mass index in children. International Journal of Pediatric Obesity, 5(5), 445-450.

Duncan, J.S., Schofield, G., \& Duncan, E.K. (2006). Pedometer-determined physical activity and body composition in New Zealand children. Medicine \& Science in Sports \& Exercise, 38(8), 1402-1409.

Duncan, J.S., Schofield, G., \& Duncan, E.K. (2007). Step count recommendations for children based on body fat. Preventive Medicine, 44(1), 42-44. 
Elder, J.P., Arredondo, E.M., Campbell, N., Baquero, B., Duerksen, S., Ayala, G., Crespo, N.C., Slymen, D., \& McKenzie, T. (2010). Individual, family, and community environmental correlates of obesity in Latino elementary school children. Journal of School Health, 80(1), 20-30.

Finnerty, T., Reeves, S., Dabinett, J., Jeanes, Y.M., \& Vögele, C. (2010). Effects of peer influence on dietary intake and physical activity in schoolchildren. Public Health Nutrition, 13(3), 376-383.

Flohr, J.A., Todd, M.K., \& Tudor-Locke, C. (2006). Pedometer-assessed physical activity in young adolescents. Research Quarterly for Exercise and Sport, 77(3), 309-315.

Hardman, K. (2008). Physical education in schools: A global perspective. Kinesiology, 40(1), 5-28.

Hohepa, M., Schofield, G., Kolt, G.S., Scragg, R., \& Garrett, N. (2008). Pedometer-determined physical activity levels of adolescents: Differences by age, sex, time of week, and transportation mode to school. Journal of Physical Activity \& Health, 5(Suppl. 1), S140-S152.

Itoi, A., Yamada, Y., Watanabe, Y., \& Kimura, M. (2012). Physical activity, energy intake, and obesity prevalence among urban and rural schoolchildren aged 11-12 years in Japan. Applied Physiology, Nutrition, and Metabolism, 37(6), 1189-1199.

Jago, R., Watson, K., Baranowski, T. Zakeri, I., Yoo, S., Baranowski, J., \& Conry, K. (2006). Pedometer reliability, validity and daily activity targets among 10- to 15-year-old boys. Journal of Sports Science, 24(3), 241-251.

Kahan, D., \& Nicaise, V. (2012). Walk as directed! Adolescents' adherence to pedometer intervention protocol. Journal of Physical Activity \& Health, 9(7), 962-969.

Kang, M., \& Brinthaupt, T.M. (2009). Effects of group- and individual-based step goals on children's physical activity levels in school. Pediatric Exercise Science, 21(2), 148-158.

Klinker, C.D., Schipperjin, J., Christian, H., Kerr, J., Ersboll, A.K., \& Troelsen, J. (2014). Using accelerometers and goal positioning system devices to assess gender and age differences in children's school, transport, leisure and home based physical activity. International Journal of Behavioral Nutrition and Physical Activity, 11, 8.

Le Masurier, G.C., \& Corbin, C.B. (2006). Steps counts among middle school students vary with aerobic fitness level. Research Quarterly for Exercise and Sport, 77(1), 14-22.

Lubans, D.R., \& Morgan, P.J. (2008). Evaluation of an extra-curricular school sport program promoting lifestyle and lifetime activity. Journal of Sports Sciences, 26(5), 519-529.

Lubans, D.R., \& Morgan, P.J. (2009). Social, psychological and behavioral correlates of pedometer step counts in a sample of Australian adolescents. Journal of Science and Medicine in Sports, 12(1), 141-147.

Lubans, D.R., Morgan, P.J., \& Tudor-Locke, C. (2009). A systematic review of studies using pedometers to promote physical activity among youth. Preventive Medicine, 48(4), 307-315.

McCormack, G.R., Rutherford, J., Giles-Corti, B., Tudor-Locke, C., \& Bull, F. (2011). BMI referenced cut-points for recommended daily pedometer-determined steps in Australian children and adolescents. Research Quarterly for Exercise and Sport, 82(2), 162-167.

Martínez-López, E.J., Grao-Cruces, A., Moral-García, J.E., \& Pantoja-Vallejo, A. (2012). Intervention for Spanish overweight teenagers in physical education lessons. Journal of Sports Science and Medicine, 11(2), 312-321.

Martínez-López, E.J., Zagalaz, M.L., Ramos, M.M., \& de la Torre, M.. (2010). Self-efficacy expectations in teacher trainees and the perceived role of schools and their physical education department in the educational treatment of overweight students. European Physical Education Review, 16(3), 251-266.

Mendoza, J., Watson, K., Nguyen, N., Cerin, E., Baranowki, T., \& Nicklas, T.A. (2011). Active commuting to school and association with physical activity and adiposity among US youth. Journal of Physical Activity and Health, 8(4), 488-495.

Michalopoulou, M., Gourgoulis, V., Kourtessis, T., Kambas, A., Dimitrou, M., \& Gretziou, H. (2011). Step counts and body mass index among 9-14 old Greek schoolchildren. Journal of Sports Science and Medicine, 10(1), $215-221$.

Olds, T.S., Ferrar, K.E., Schranz, N.K., Maher, C.A. (2011). Obese adolescents are less active than their normal-weight peers, but wherein lies the difference? Journal of Adolescent Health, 48(2), 189-195.

Richardson, C.R., Newton, T.L., Abraham, J.J., Sen, A., Jimbo, M., \& Swartz, A.M. (2008). A meta-analysis of pedometer-based walking interventions and weight loss. Annals of Family Medicine, 6(1), 69-77.

Rodearmel, S.J., Wyatt, H.R., Stroebele, N., Smith, S.M., Ogden, L.G., \& Hill, J.O. (2007). Small changes in dietary sugar and physical activity as an approach to preventing excessive weight gain: The America on the Move Family Study. Pediatrics, 120(4), 869-879.

Senne, T., Rowe, D., Boswell, B., Decker, J., \& Douglas, S. (2009). Factors associated with adolescent physical activity during middle school physical education: A one-year case study. European Physical Education Review, 15(3), 295-314.

Smith, L., Sahlqvist, S., Ogilvie, D., Jones, A., Corder, K., Griffin, S.J., \& van Sluijs, E. (2012). Is a change in mode of travel to school associated with a change in overall physical activity levels in children? Longitudinal results from the SPEEDY study. International Journal of Behavioral Nutrition and Physical Activity, 9, 134.

Trost, S.G., Pate, R.R., Freedson, P.S., Sallis, J.F., \& Taylor, W.C. (2000). Using objective physical activity measures with youth: How many days of monitoring are needed? Medicine \& Science in Sports \& Exercise, 32(2), 426-431.

Tudor-Locke, C., \& Bassett, D.R. (2004). How many steps/day are enough? Preliminary pedometer indices for public health. Sports Medicine, 34(1), 1-8. 
Tudor-Locke, C., Craig, C.L., Cameron, C., \& Griffiths, J.M. (2011). Canadian children's and youth's pedometerdetermined steps/day, parent-reported TV watching time, and overweight/obesity: The CANPLAY Surveillance Study. International Journal of Behavioral Nutrition and Physical Activity, 8, 66.

Tudor-Locke, C., Lee, S.M., Morgan, C.F., Beighle, A., \& Pangrazi, R.P. (2006). Children's pedometer-determined physical activity during the segmented school day. Medicine \& Science in Sports \& Exercise, 38(10), 1732-1738.

Tudor-Locke, C., Pangrazi, R.P., Corbin, C.B., Rutherford, W.J., Vincent, S.D., Raustorp, A., Tomson, L.M., \& Cuddihy, T.F. (2004). BMI-referenced standards for recommended pedometer-determined steps/day in children. Preventive Medicine, 38(6), 857-864.

Vicent, S.D., Pangrazi, R.P., Raustorp, A., Tomson, L.M., \& Cuddihy, T.F. (2003). Active levels and body mass index of children in the United States, Sweden, and Australia. Medicine \& Science in Sport \& Exercise, 35(8), 1367-1373.

Viira, R., \& Koka, A. (2012). Participation in afterschool sport: Relationship to perceived need support, need satisfaction, and motivation in physical education. Kinesiology, 44(2), 199-208.

World Health Organization. (2010). Global recommendation on physical activity for health. Geneva: World Health Organization.

Submitted: February 1, 2015

Accepted: March 8, 2016

Correspondence to:

Emilio J Martínez-López, Ph.D.

Department of Didactic of Musical,

Plastic and Corporal Expression

School of Educational Sciences (D-2),

University of Jaén

Las Lagunillas Campus, 23071 Jaén, Spain

Phone: (+34) 953212488

Fax: (+34) 953211880

E-mail: emilioml@ujaen.es 